\title{
'Gente Borgia'. Un nuevo ejemplo del mecenazgo de los Borja: Primeras inscripciones humanísticas en Valencia
}

\section{'Gente Borgia'. Anew example of Borja's patronage: First humanistic inscriptions in Valencia}

\author{
Vicente Pons Alós \\ vicente.pons-alos@uv.es \\ Universitat de València
}

\begin{abstract}
Resumen: Escritura y heráldica se convierten en un lenguaje fundamental al servicio institucional y personal de los Borja, que desde Italia llegará también a su ciudad de origen y a sus señoríos. En Xàtiva y Gandía respectivamente se conservan las primeras inscripciones humanísticas que podemos ubicar en territorio valenciano. En ambos casos se trata de piezas vinculadas a la familia Borja y las dos se encuentran en el ámbito de las colegiatas de estas dos ciudades: en la capilla dedicada a Nuestra Señora de las Fiebres, advocación romana, cuya construcción mandó llevar a cabo en 1497 Francesc de Borja, tesorero pontificio, obispo de Teano, más tarde arzobispo de Cosenza y cardenal nombrado por Alejandro VI; y en el exterior de la colegiata de Santa María de Gandía, erigida en 1499 por Alejandro VI, a ambos lados de la puerta de los Apóstoles, construida bajo los auspicios de María Enríquez, viuda sucesivamente de Pere Lluís de Borja y Joan de Borja, hermanos, I y II duques de Gandía. La duquesa viuda reemprendió el proyecto inconcluso de la colegiata que quedará acabado, como señalan las inscripciones, en 1500, bajo su mecenazgo y el de su hijo Joan de Borja, III duque.
\end{abstract}

Palabras clave: Inscripciones humanísticas, Historia de la Iglesia, Heráldica, Alejandro VI.

Abstract: Writing and heraldry become a fundamental language to the institutional and personal service of the Borjas. They did not only used in Italy but also in their city of origin and their manors. Both in Xàtiva and Gandía we find the first humanistic inscriptions located in Valencian territory In both cases they are pieces linked to the Borja family and the two are found in the collegiate area of these two cities: in the chapel dedicated to the Mare de Déu de les Febres, a Roman dedication, whose construction was ordered in 1497 by Francesc de Borja, pontifical treasurer, bishop of Teano, later archbishop of Cosenza and cardinal appointed by Alexander VI; and outside of the church of Santa María de Gandía, erected as collegiate in 1499 by Alejandro VI, on both sides of the door of the Apostles, built under the auspices of María Enríquez, widow successively of Pere Lluís de Borja and Joan de Borja, brothers, I and II Borja dukes of Gandía. The duchess widow resumed the unfinished project of the collegiate church that will be finished, as indicated by the inscriptions, in 1500, under his patronage and that of his son Joan, III Borja Duke.

Keywords: Heraldry, Humanistic inscription, Alexander VI, Church history

\footnotetext{
* Este trabajo ha sido realizado con la ayuda del Centro Español de Estudios Eclesiásticos, anejo a la Iglesia Nacional Española de Santiago y Montserrat en Roma, en el marco de los proyectos de investigación del curso 2016-17 y 2017-18.
} 
Vicente Pons Alós. ‘Gente Borgia’. Un nuevo ejemplo del mecenazgo de los Borja: Primeras inscripciones humanísticas en Valencia

Gente Borgia-de la familia Borja-, es una de las expresiones que aparece en un número importante de inscripciones de la época de Alejandro VI en Roma. El término tiene una trascendencia mayor que su propio significado literal, supone también la instrumentalización de las escrituras de aparato por parte del segundo papa Borja no sólo al servicio del poder del pontífice, como los papas anteriores y posteriores, ${ }^{1}$ sino también al servicio del prestigio y enaltecimiento del propio linaje, más aún en un pontificado donde la autoridad eclesiástica del papa quedará difuminada ante su autoridad civil: «reafirmó el poder papal en una serie de prestigiosos y llamativos proyectos, promoviendo su imagen como soberano secular y como líder militar de los Estados pontificios» (Paolucci 2016). ${ }^{2}$ Escritura y heráldica se convertían en lenguaje fundamental en la Europa renacentista al servicio institucional y personal de los Borja, que desde Italia llegará también a su ciudad de origen y a sus señoríos. En Xàtiva y Gandía respectivamente se conservan las primeras inscripciones humanísticas que podemos ubicar en territorio valenciano. En ambos casos se trata de piezas vinculadas a la familia Borja y las dos se encuentran en el ámbito de las colegiatas de estas dos ciudades. En el interior de la colegiata de Santa María de Xàtiva, erigida por Benedicto XIII en 1414, se encuentra en la pared lateral de la actual capilla de Nuestra Señora de la Soledad, una primera inscripción humanística conmemorativa, aunque hasta el s. XVIII se localizaba en otra capilla dedicada a Nuestra Señora de las Fiebres, advocación romana, cuya construcción mandó llevar a cabo en 1497 Francesc de Borja, tesorero pontificio, obispo de Teano, más tarde arzobispo de Cosenza y cardenal nombrado por Alejandro VI. ${ }^{3}$ Su formación y su relación con los grandes personajes de la cultura humanística italiana queda demostrada en la dedicación que Pomponio Leto le hace de su obra Compendio de Antigüedades Romanas, y su patrocinio de la edición de la obra de Jeroni Pau: Practica Cancellariae Apostolicae (Roma 1493). Él mismo era un gran humanista, como lo prueban los frecuentes préstamos de libros de la Biblioteca Vaticana, entre otros el códice de la Vita Pontificum de Platina (Niutta 2002). ${ }^{4}$

Otras dos inscripciones humanísticas se encuentran en el exterior de la colegiata de Santa María de Gandía, erigida en 1499 por Alejandro VI, a ambos lados de la puerta de los Apóstoles, construida bajo los auspicios de María Enríquez, viuda sucesivamente de Pere Lluís de Borja y Joan de Borja, hermanos, I y II duques de Gandía, destruida en gran parte en 1936. La duquesa viuda reemprendió el proyecto inconcluso de la colegiata que quedará acabado, como señalan las inscripciones, en

1 Para el pontificado de Alejandro VI, vid. Gargano (2001).

2 La representación de las antiguas divinidades egipcias de Isis y Osiris, de las cuales descendía según Annnio de Viterbo, su maestro del Sacro Palacio, el mismo Alejandro VI, decoraron una parte de la bóveda de sus aposentos, reforzando la imagen del Papa Borja como soberano secular. El manso buey parlante del escudo de los Borja valencianos se convirtió en un robusto buey, asimilado a algunas representaciones antiguas (Hollingsworth 2002).

3 Para esta capilla mandó pintar el mismo Francesc de Borja a Bernardino di Betto, il Pinturicchio, una magnífica tabla con esta advocación, conservada hoy en el Museo de Bellas Artes San Pio V de Valencia. Sobre el personaje y la inscripción vid. Pons Alós (2005) y González Baldovi (2014). Sobre la Colegiata de Xàtiva vid. Pons Alós (2013); Pérez Giménez (2014); Bertaux (1908: 89-113, 198-220).

4 Sobre Jeroni Pau, vid. Pau (1986).

SCRIPTA, Revista internacional de literatura i cultura medieval i moderna, núm. 13 / juny 2019 / pp. 22 - 44 ISSN: 2340-4841 $\cdot$ doi:10.7203/SCRIPTA.13.15474 
Vicente Pons Alós. ‘Gente Borgia’. Un nuevo ejemplo del mecenazgo de los Borja: Primeras inscripciones humanísticas en Valencia

1500, bajo su mecenazgo y el de su hijo Joan de Borja, III duque. ${ }^{5}$ No es ninguna casualidad que sea en enero de dicho año cuando se trasladen los restos de los dos primeros duques desde Santa María del Popolo en Roma a Gandía.

El contraste entre la escritura mayúscula humanística y el carácter aún de transición del gótico al renacimiento que presenta la puerta de la colegiata de Gandía, obra de Damià y Onofre Forment, declara ya no sólo lo atípico de estas inscripciones humanísticas tan tempranas, sino su procedencia foránea. Ambos epígrafes fueron realizados en los talleres de Roma, también bajo los auspicios de los Borja. Aunque Damià Forment es considerado un escultor renacentista y tanto la Virgen del parteluz de esta portada, como las figuras de san Pedro y San Pablo de sus jambas laterales, presentan ya un claro clasicismo, habrá que esperar a sus obras posteriores para que emplee las mayúsculas humanísticas. Así, mientras en las filacterias del retablo del convento de la Puridad de Valencia (1500-15), conservado en el museo de Bellas Artes, utiliza todavía minúsculas góticas, en el retablo mayor de la basílica de El Pilar de Zaragoza (1509-18) y en el de Santo Domingo de la Calzada (1537-42) emplea ya capitales humanísticas. ${ }^{6}$

La comparación de las inscripciones de Xàtiva y Gandía (lám. 4-7), con las que se encuentran dispersas en diferentes ámbitos de la Ciudad Eterna de esta misma época (1497-1500) (lám. 1-3), y otros enclaves Borgianos de Italia, como Civitavechia, sitúa su procedencia en los mismos talleres romanos. Sólo en Roma y en otras ciudades italianas encontramos epígrafes con una mayúscula humanística epigráfica tan elegante y con materiales nobles tan especiales: en la Roca de Subiaco (1476), en Castello de Sant'Angelo (1495), en muchas calles y edificios de Roma, o en detalles concretos como la chimenea de los apartamentos Borja, hoy una de las salas de los Museos Vaticanos (Chiabo \& Gargano 2003). ${ }^{7}$

Para Castilla, Manuel Ramírez Sánchez ha estudiado detalladamente la introducción de la escritura humanística en las inscripciones en los siglos XV y XVI, editando y describiendo los primeros epígrafes en capital humanística, entre ellos los del sepulcro del cardenal Mendoza (+1495) en la catedral de Toledo, de Diego Hurtado de Mendoza (+1502) en la catedral de Sevilla y del príncipe don Juan (+1497), en la iglesia del monasterio de Santo Tomás de Ávila, ambas de principios del s. XVI, obra del italiano Domenico Fancelli, el mismo escultor del epitafio situado a los pies del sepulcro de los Reyes Católicos en la Capilla real de Granada. M. Ramírez señala que hay que esperar al reinado de Carlos V (1516-1556) para observar la «definitiva implantación de las capitales

5 Sobre la colegiata de Gandía vid. Herrero (2002), especialmente el artículo de Pellicer i Rocher \& Company i Climent (2002: 65-128); y Pellicer i Rocher (2011). Sobre los Borja, duques de Gandía, vid. Batllori (1994); y Pastor Zapata (1992).

6 Sobre la obra de Damià Forment, vid. AAVV (1995). Ilustraciones en pp. 110-111, 136, 192, 244, 252-253.

7 Sobre una inscripción en la puerta Borja con los restos del sepulcro de Glizio Gallo de la época del cardenal Rodrigo de Borja (1476) en Subiaco vid. Villalonga (1982). Vid también el catálogo de la exposición: I Borgia, 2002, especialmente pp. 127, 164-165.

SCRIPTA, Revista internacional de literatura i cultura medieval i moderna, núm. 13 / juny 2019 / pp. 22 - 44 ISSN: 2340-4841 · doi:10.7203/SCRIPTA.13.15474 
Vicente Pons Alós. ‘Gente Borgia’. Un nuevo ejemplo del mecenazgo de los Borja: Primeras inscripciones humanísticas en Valencia

humanísticas en la epigrafía de aparato, dando fin al multigrafismo imperante en las primeras décadas del siglo» (Ramírez Sánchez 2012). ${ }^{8}$ Al igual que para Valencia, las primeras inscripciones en capital humanística en Castilla proceden de talleres italianos o se realizan por operarios procedentes de allí.

\section{Un programa epigráfico al servicio de los papas}

Según Forcella, en Roma sólo se encontraban cuatro inscripciones en escritura estrictamente gótica posteriores a 1430. La última escrita en gótica, todavía conservada, de 1488, se refiere a un difunto holandés, y se encuentra hoy en la basílica de San Pedro (Forcella 1869-1884). ${ }^{9}$ En la segunda mitad del s. XIV se consolida en Italia el interés por los epígrafes clásicos como documentos culturales de naturaleza literaria, filológica, histórica y gráfica (Porro 1986; Nyberg 1986; Campana 2005; Zamponi 2004; Casamassina 1964). A. Petrucci ha estudiado las causas ideológicas y políticas de la aparición de estas inscripciones «publicas», que imitan los modelos antiguos y que forman parte de un programa grafico monumental (Petrucci 1985, 1986, 1994). No se trata solo de una imitación y renovación cuatrocentista de la capital a imitación de lo antiguo, propugnada por la cultura humanística, se trata de un nuevo programa epigráfico de una escritura acorde con la magnificencia de los monumentos, que asume una marcada impronta ideológica y que en Roma estará al servicio de los Papas (Paolucci 2016: 27-38; Kajanto 1982 y 1989; Gionta 2005). Hay que esperar a la segunda mitad del s. XV, para encontrar lo que Paolucci ha denominado un «nuevo estilo epigráfico», en el que la obra Alphabetum Romanum de Felice Feliciano (c. 1460) es fundamental, y en el que se enmarcan las inscripciones del pontificado de Alejandro VI (casamassima 1966). ${ }^{10}$

Una primera época vendrá caracterizada por la imitación de la capital romana, pero con abundante uso de abreviaturas y presencia de elementos góticos. Todavía en 1422 y 1423 una inscripción de la fachada de Santa María de Minerva, que documenta una riada del Tiber con Martín V, y otra del cardenal Alfonso Carrillo en la torre de la iglesia de los santos cuatro Coronados utilizan la minúscula gótica. De transición se consideran el epitafio del sepulcro de Alfonso Pardinas sobre el portal de la iglesia de Santiago de los Españoles (1440), una capital de imitación de la antigua, o los epígrafes de Nicolás V en el palacio de Capranica (1451) y de Calixto III en el ponte Milvio (1458). Una inscripción en el arquitrabe de la entrada a la iglesia de San Esteban Rotondo, restaurada por Nicolás V (1453), supone ya una segunda etapa con una capital humanística ya definida. El abandono de los caracteres góticos se inicia en torno a 1430, así la inscripción en bronce de Martín V (+1431) en San Juan de Letrán es considerada el primer caso de empleo de la capital romana en el Renacimiento. Treinta años después, en 1465, el sepulcro del cardenal Luis d'Albret en Santa María in Aracoeli es ya un ejemplo de

\footnotetext{
8 Vid. también Castillo Gómez (1997) y Pereira García (2016).

9 Sobre inscripciones de españoles en Roma, Tormo Monzó (1942).

10 Sobre este tema vid. Gimeno Blay, 2002; Id., 2005; Id., 2015.
}

SCRIPTA, Revista internacional de literatura i cultura medieval i moderna, núm. 13 / juny 2019 / pp. 22 - 44 ISSN: 2340-4841 · doi:10.7203/SCRIPTA.13.15474 
Vicente Pons Alós. 'Gente Borgia'. Un nuevo ejemplo del mecenazgo de los Borja: Primeras inscripciones humanísticas en Valencia

la consolidación de la capital humanística epigráfica en Roma, que coincide con el pontificado de Sixto IV y que dará lugar a lo que se ha venido en llamar epigrafía Sixtina (1471-1484), caracterizada por una búsqueda de la armonía estilística, una geometría perfecta, que facilitase la legibilidad y la visibilidad de los textos al servicio del poder. De esta nueva etapa, que tiene su centro en el pontificado del conocido como Doctor acutissimus, son ejemplos las dos inscripciones procedentes del puente sixtino, con motivo de su inicio en 1474, hoy entre los fondos del ayuntamiento de Roma, y las dos bulas de indulgencia lapidarias de Santa María del Popolo (1472). ${ }^{11}$

Con Sixto IV se intensifica el uso de las inscripciones y se amplía su tipología con un fin propagandístico sabiendo cual era la potencialidad del medio epigráfico: la inscripción capitolina de 1471 será el primer ejemplo de este nuevo uso, una inscripción que suponía una novedad en el panorama epigráfico de Roma, tanto por su género, como por su contenido y colocación. Se trata de la primera inscripción pública -en el Campidoglio- de su pontificado correspondiendo a la donación de las antiguas esculturas de bronce, ya en el Laterano. El Papa devolvía a la ciudad de Roma, heredera de la Roma antigua: restituendas condonandasque, estas imágenes clásicas, algo más que un simple gesto (Niutta 1986; Guerrini 1986; Guerrrini \& Maddalo \& Niutta \& Porro 1986)..$^{12}$ En opinión de A. Petrucci, es difícil saber quién es el introductor de la capital epigráfica humanística en Roma, pero sin duda tuvo un protagonismo destacado el escultor lombardo Andrea Bregno, autor de muchas obras en la ciudad, al cual, como ya hemos indicado, se adscribe la más antigua litterae epigráfica en el monumento fúnebre del cardenal Ludovico d'Albret (+1465), en Santa María in Aracoeli, articulada en tres formatos diferentes de letras y con un claroscuro que le identifica (Petrucci 1985: 85-97).

En este marco se inscriben las inscripciones romanas del periodo de Alejandro VI (1492-1503). A pesar de las pérdidas, destrucción y dispersión de muchos epígrafes del segundo papa Borja, ocurridas tras su muerte y favorecidas por la leyenda negra que le acompañó, pero también realizadas con la ocupación napoleónica, ${ }^{13}$ todavía se conservan algunas magníficas inscripciones de su pontificado, con una escritura, materiales y factura idénticas a las conservadas en Xàtiva y Gandía. Las del Castel Sant'Angelo, fortaleza militar y residencia pontificia, estancias Borja del Vaticano, las ubicadas en diferentes calles: via dei Corridori, Piazza della Suburra, via del Pellegrino (1495) o via della Palambella (1495), en la mayoría de las cuales se hace presente una jerarquía grafica con el nombre del papa más grande que el resto del texto y destacando, como en los códices, la A inicial. ${ }^{14}$

11 Todas estas inscripciones están documentadas en Paolucci (2016).

12 Sobre la influencia en España, vid. Redondo Cantera (1986).

13 Por ello, no es de extrañar que muchos repertorios clásicos de inscripciones de Roma no hagan referencia a las del pontificado de Alejandro VI (Galletti Romani, 1760). Sobre el castillo de Sant'Angelo vid. Onofrio (1978: esp. 256-268).

14 Vid. láminas 1, 2, 3.

SCRIPTA, Revista internacional de literatura i cultura medieval i moderna, núm. 13 / juny 2019 / pp. 22 - 44 ISSN: 2340-4841 $\cdot$ doi:10.7203/SCRIPTA.13.15474 
Vicente Pons Alós. ‘Gente Borgia’. Un nuevo ejemplo del mecenazgo de los Borja: Primeras inscripciones humanísticas en Valencia

\section{Primeras inscripciones humanísticas en Valencia}

En Valencia, la llegada de documentos, códices e inscripciones en escritura humanística, realizados en Italia, precedió al desarrollo de una producción propia en ese tipo gráfico (Mandingorra Llavata 1980). Francisco Gimeno ha estudiado con detalle el periodo de transición en Valencia en el que «junto a las minúsculas góticas textuales, aparecen unas mayúsculas capitales que parecen ser, simplemente, el resultado de una imitación de las románicas, ya que no participan todavía de la elegancia clásica que mostrarán las de la primera mitad del s. XVI» (Gimeno Blay, 2002; 2002b; 2005; 2008). ${ }^{15} \mathrm{El}$ mismo ha estudiado con detalle la filacteria de la pintura que preside todavía la Virgen de la Sapiencia entre San Nicolás y San Lucas en la capilla del edificio histórico de la Universidad de Valencia (1517), investigación que le ha llevado a demostrar que sólo desde principios del s. XVI se empiezan a utilizar mayúsculas humanísticas en la pintura valenciana (Giemno Blay 2008). Excepcionales son las capitales del fresco del «florentino Nicolás» en palabras de J. Sanchis Sivera, obra de un italiano, hoy en la capilla del Santo Cáliz de la catedral de Valencia, antigua aula capitular; ${ }^{16}$ las capitales del friso de la Lonja de Valencia ${ }^{17}$ o las toscas mayúsculas del sarcófago de Galceran Pardo de la Casta en el Museo de Bellas Artes, ambas ya de principios del s. $\mathrm{XVI} .{ }^{18}$ Hay que esperar ya a la inscripción de una de las puertas del actual palacio de la Generalitat, procedente del castillo de Montesa, y que fr. Francesc Llançol de Romaní, mestre de Montesa (1537-1544), mandó esculpir (lám. 8), ${ }^{19}$ a los textos que acompañan las sepulturas de los marqueses

15 Véase también un catálogo y edición de las inscripciones góticas conservadas en la ciudad de Valencia en Gimeno Blay (1990). Un intento de inventario de inscripciones medievales y modernas también en Bolufer \& Ribera (1999).

16 Sanchis Sivera (1909), lám. 40 y 41. En esta segunda lámina el canónigo de la catedral reconstruye la pintura representando la adoración de los magos, y transcribe la inscripción que la envuelve: «UBI EST QUI NATUS EST REX IUDEORUM. /GAUDE QUOD OBLACIO REGUM ET DEVOCIO EXHIBETUR/ FILIO. VIDIMUS STELLAM EIUS IN ORIENTE/ ET VENIMUS CUM MUNERIBUS ADORARE DOMINUM», que incluye en parte textos bíblicos y una de las estrofas de los Gaudes de la Virgen que se cantan en la Catedral desde época de Alfonso de Borja-Calixto III.

17 INCLYTA DOMUS SUM, ANNIS EDIFICATA QUINDECIM. GUSTATE ET VIDETE, CONCIVES, QUONIAM BONA EST NEGOCIACIO QUE NON AGIT DOLUM IN LINGUA SUA, QUE IURAT PROXIMO ET NON DECIPIT, QUE PECUNIAM NON DEDIT AD USURAM E(i)US. MERCATORES SIC DEGENS DIVICIIS REDUNDABIT, ET TANDEM VITA FRUETUR ETERNA, texto basado en los textos bíblicos Pr 31, 18; Lv 25, 37 y Ap 18, 3 (Pons Alós, 2014). Sobre la Lonja de mercaderes de Valencia vid. también Aldana Fernández (1988).

18 Sin ningún elemento de adorno, y en un sencillo sarcófago de dos piezas, con la inscripción, datada para finales del s. XV, aunque debe ser posterior y casi con seguridad del s. XVI: IE(s)US/HIC $\cdot$ IACET $\cdot \mathrm{D}($ omi)N(U)S $\cdot \mathrm{DON}$ GALCERAN/DUS PARDO ET DDE VILANOVA (Valencia. Museo de Bellas Artes, no catálogo 1565). Este tipo de inscripciones sepulcrales sencillas responde a la voluntad de muchos nobles a finales del s. XV y XVI. Así, en 1485, Mateu de Montcada, señor de Villamarxant, dispone en su testamento que sobre su cuerpo: «sia posat una losa o pedra ab les armes de Montcada, en la qual sien sculpìdes tals o semblants letres e titol: Açi iau don Matheu de Moncada» (Archivo Condal de Orgaz. Fondo Crespí de Valldaura. Leg. LL-6). Sobre los Pardo de la Casta vid. Juan Redal - Juan Caballer, 2009.

19 FRATER FRANCISCUS LLANCOL DE / ROMANI, MAGISTER MONTESIE. Contrasta con esta escritura capital humanística la inscripción del anterior mestre de Montesa: Bernat Despuig (1506-1537), procedente también del

SCRIPTA, Revista internacional de literatura i cultura medieval i moderna, núm. 13 / juny 2019 / pp. 22 - 44 ISSN: $2340-4841 \cdot$ doi:10.7203/SCRIPTA.13.15474 
Vicente Pons Alós. ‘Gente Borgia’. Un nuevo ejemplo del mecenazgo de los Borja: Primeras inscripciones humanísticas en Valencia

de Cenete en el convento de Santo Domingo (1535), ${ }^{20}$ o los epígrafes de los sepulcros de los arzobispos de Valencia Tomás de Villanueva (+1555), procedente del convento agustino de Socors (lám. 9), ${ }^{21}$ o Martín López de Ayala (+1566) (Sanchis Sivera, 1909: 240 y lám. 42; Martínez Talón 2017), de Diego de Covarrubias (+1607) y su mujer, todas ellos conservados hoy en el ámbito de la Catedral de Valencia (Sanchis Sivera 1909: 261-263; Martínez Talón, 2017), para encontrar ya escrituras humanísticas, aunque en algunos de estos casos, como las del mestre Llançol de Romaní y la del agustino fr. Tomás de Villanueva, también la factura parece italiana, o por lo menos de artistas italianos establecidos ya en Valencia.

El panorama epigráfico del reino de Valencia analizado demuestra que las inscripciones de Xàtiva y Gandía, en escritura mayúscula humanística, son excepcionales. Procedentes en ambos casos de talleres romanos, presentan interpunción triangular colocada en el centro de la línea y no quedan restos de ordinatio. A través de la incisión de surco en v y de refuerzos en todas las letras se consigue un fuerte contraste. La inscripción de Xàtiva utiliza tres abreviaturas por truncamiento y da una especial elegancia a las Q, que alargan su trazo secundario hasta la letra siguiente. Por razones de espacio y puramente estéticas, pero también en honor del comitente, realza la F inicial del epígrafe y la T de «Monumentum». Este juego de las letras para cuadrar el espacio gráfico sin romper la estética de la escritura se repite en la inscripción del mestre de Montesa, donde la segunda «l» de

castillo de Montesa y conservada hoy en la iglesia del Temple de Valencia, que utiliza todavía una escritura minúscula con elementos todavía de tradición gótica (Cerda i Ballester \& Navarro Fajardo, 2017).

20 Escolano transcribe las inscripciones, tanto de los magníficos sepulcros de Rodrigo de Mendoza, marqués de Cenete, y de su mujer María Fonseca, como la de su hija Mencía de Mendoza, puesta sobre la losa de su sencilla sepultura a los pies de las de sus padres (Escolano \& Perales, 1878-1880, II: 630). Ella mismo había dispuesto en su testamento en 1535, diecinueve años antes de su muerte «que sobre mi sepultura se ponga una lancha de alabastro igual que la tierra, sin otro bulto, con un letrero en que se diga como mi cuerpo yace allí sepultado, y se declare el día de mi finamiento, porque las personas que lo vieren y leyeren y me conocieren en esta vida, tengan memoria de rogara a Dios por mi anima» (Gascón Pelegrí 1975: 90-91). Vid. también García (2004; 2007-2008: 63-74).

21 Se trata de una inscripción sepulcral sobre una gruesa losa de mármol blanco (212 x 103 x 13 cms). Colocada hoy en la capilla de santo Tomás de Villanueva de la catedral de Valencia, procede del convento de agustinos de Nuestra Señora del Socorro de Valencia. Seguramente a partir de la exhumación de sus restos, tras su beatificación y canonización, y especialmente con la desamortización del s. XIX, pasó a propietarios particulares. Los actuales propietarios, don Vicente Cardells y doña Asunción Galea, donaron el año 2005 a la Iglesia Catedral la lápida sepulcral, que se encontraba en una casona de Rocafort. Su estado de conservación es bueno, salvo algunas partes picadas y algunos faltantes, especialmente en el rostro del obispo, una parte de su mano y el extremo del báculo. Requiere igualmente una limpieza. La calidad del mármol, la escritura utilizada y los detalles de la imagen esculpida y elementos heráldicos parecen indicar que se trata también de una obra de procedencia o factura italiana. El texto de la inscripción funeraria aparece bordeando toda la losa rectangular en una perfecta mayúscula humanística epigráfica. Presenta ordinatio y una interpunción triangular, que separa las diferentes partes del texto. El signo de abreviación tiene forma de yugo y adquieren formas características las letras Q y la O: CONDITUR HOC TUMULO DON FRAY THOMAS DE VILLA-/-NUEVA, · AR CHIEPISCOPUS · VALENTINUS, · DIVINI VERBI PREDICATOR EXIMUS, QUI CHRISTI PAUPERES BENIGNA QUIDE(m) / MANU NON SOLUM VIVENS FOVIT · SED AD EXTREMUM / USQUE SPIRITUM AMPLISSIMIS ELEEMOSYNIS PROSEQUUTUS EST. · OBIIT AUTEM DIE NATIVITATIS VIRGINIS MARIE ANNO 1555 (Martínez Talón, 2017).

SCRIPTA, Revista internacional de literatura i cultura medieval $i$ moderna, núm. 13 / juny 2019 / pp. 22 - 44 ISSN: 2340-4841 · doi:10.7203/SCRIPTA.13.15474 
Vicente Pons Alós. 'Gente Borgia'. Un nuevo ejemplo del mecenazgo de los Borja: Primeras inscripciones humanísticas en Valencia

Llançol se inserta dentro de la primera. Las de Gandía presentan más abreviaturas, en su absoluta mayoría por truncamiento y sólo una por contracción: «quingentesi(m)o», que se repite en ambas lápidas. La totalidad de sus letras, a diferencia de la de Xàtiva, se enmarca entre dos líneas, sin destacar ninguna de ellas. Sólo coloca la segunda «l» de la abreviatura de «Ill(ustris)» dentro de la primera, al igual que en la inscripción del mestre de Montesa. El complejo sistema de abreviación en las inscripciones góticas era sustituido por el sistema clásico, basado fundamentalmente en la suspensión de los finales de palabra, aunque este cambio no fue radical, sino progresivo.

En un correcto latín, también la forma de indicar el tiempo cambió con la nueva escritura y los nuevos textos, que en todos los casos estudiados aquí son conmemorativos: Anno Salutis para Xàtiva, anno post Iesu natalem y anno quingentesimo supra mil(esimo) post Virginem enixam, para Gandía. Un mismo sistema, el anno a nativitate Domini, pero ahora expresado de forma distinta.

El campo epigráfico está enmarcado por su respectiva moldura, de las que sólo parece original la de Xàtiva. La circunstancia de que las inscripciones de la colegiata de Gandía se encuentren en el exterior justifica su deterioro, aunque sin impedir la legibilidad.

\section{Las transformaciones en la heráldica como elemento complementario}

Junto con la escritura, otro elemento importado desde Italia, en el que jugaran también un papel importante los Borja, será los nuevos usos y formas en la heráldica, perfectamente visibles ya en los tres escudos borgianos de Calixto III y su sobrino Rodrigo de Borja, de la puerta del palacio del ardiaca de Xàtiva (1455-58). ${ }^{22}$ La lápida puesta encima de la inscripción de Xàtiva del obispo de Teano, aparece insertada igualmente en una moldura doble, y responde claramente a los cánones heráldicos y artísticos del ámbito italiano donde se realizó. La misma boca, el mismo buey y la misma composición heráldica que los escudos de Alejandro VI, entre otros lugares de Roma, y de forma abundante, en el Castell Sant'Angelo, o en la torre Borja, junto a la plaza de San Pedro. Se trata de un escudo de boca o forma irregular a la italiana. En el campo un buey pastando sobre un terrazado, con bordura con doce botjes, representadas como espigas de trigo, armas parlantes de los Borja. La cabeza del buey penetra en la bordura, donde una de las espigas se ha convertido en una mata de hierba. Por timbre, lleva una mitra con dos ínfulas al vuelo, símbolo de la dignidad episcopal. En 1497, cuando se hizo la inscripción, todavía no había sido nombrado arzobispo y cardenal.

También las inscripciones de Gandía van acompañadas de elementos heráldicos, pero esta vez dos escudos simétricos colocados en la misma puerta llamada de los Apóstoles, a ambos lados del mainel, con las armas de los Borja y de los Enríquez (escudos de boca italiana, cuartelados en cruz: $1^{\circ} \mathrm{y}$ $4^{\circ}$ armas de los Borja -partido, primero: un buey pasante con bordura al todo cargada de 8 haces;

22 Sobre heráldica borgiana vid. Pons Alós (1996, 2002); Borgia (2001); Montesano (2001); I Borgia (2002: esp. 170-171).

SCRIPTA, Revista internacional de literatura i cultura medieval $i$ moderna, núm. 13 / juny 2019 / pp. 22 - 44 ISSN: 2340-4841 · doi:10.7203/SCRIPTA.13.15474 
Vicente Pons Alós. ‘Gente Borgia’. Un nuevo ejemplo del mecenazgo de los Borja: Primeras inscripciones humanísticas en Valencia

segundo: fajado, tres de oro y tres de gules-, $2^{\circ}$ y $3^{\circ}$ armas de los Enríquez -mantelado: primero y segundo sendos castillos, tercero, león rampante), ambos -en expresión de X. Company- representan uno de los primeros ejemplos de ornamentación renacentista con influencias claramente italianas.

Sin duda alguna, el episcopado de Rodrigo de Borja y más tarde su llegada al papado como Alejandro VI, supone también el inicio de la llegada primero y del uso in situ después de nuevas formas y esquemas heráldicos. La tradicional boca acabada en punta, siguiendo la moda francesa, de los escudos medievales, y la práctica totalidad de armerías parlantes, dará paso con la conquista de Nápoles por parte del Magnánimo y con los Borja a formas más complejas siguiendo los modelos italianos tanto en la forma, como en las figuras y particiones. Así ocurre con la boca del escudo de Rodrigo de Borja como abad de Valldigna (1476-1491), o en los restos heráldicos como obispo de Valencia encontrados recientemente con la restauración de la actual capilla de San Pedro de la catedral de Valencia. Estos cambios heráldicos se verán especialmente en la cerámica, tanto en la realizada en los hornos de Manises con destino a las estancias Borja de San Pedro de Roma, como en los azulejos que quedan todavía aquí bien en el convento de la Encarnación o en el Museo González Martí, y que serán imitados más tarde en Valencia para el pavimento de otras casas nobiliarias. ${ }^{23}$ Los cambios en la heráldica valenciana por influencia italiana llevaran también al uso de divisas, enigmas, figuras antropomorfas y tenantes. El ejemplo más claro lo supone el escudo de Eximen Pérez Rois de Corella (+1457), conde de Cocentaina y loctinent de general governador de Valencia al añadir a sus armas tradicionales, tras su estancia en Nápoles, además de las concedidas por el rey, la divisa: Esdevenidor, y una serpiente con cabeza humana en torno a la boca de su escudo (Pons Alós 1997: esp. 99).

\section{A modo de conclusión}

Hay que decir que los primeros epígrafes en mayúscula humanística, al igual que impresores, pintores y escultores, llegaron a Valencia procedentes de Roma y del resto de estados italianos coincidiendo con el posicionamiento de los Borja en la curia pontificia, la visita de Rodrigo de Borja a su diócesis como cardenal y nuncio papal en 1472, pero especialmente con su pontificado como Alejandro VI (1492-1503). Todos ellos, e incluso los posteriores de Llançol de Romaní y Tomás de Villanueva son obra de talleres italianos. También las formas y usos heráldicos cambiaran bajo la influencia de los Borja, aunque en este segundo caso hay que tener en cuenta también las especiales relaciones Valencia-Italia desde el reinado del Magnánimo. Las inscripciones de Xàtiva y Gandía son, sin duda, las primeras en una perfecta mayúscula humanística que podemos encontrar en la Península Ibérica.

23 Gonzalez Martí, 1952, pp. 621-653; I Borgia, 2002, especialmente pp. 170-171. 
Vicente Pons Alós. ‘Gente Borgia’. Un nuevo ejemplo del mecenazgo de los Borja: Primeras inscripciones humanísticas en Valencia

\section{Apéndice documental}

$-1-$

1497. Inscripción conmemorativa de la fundación de la capilla de la Mare de Déu de les Febres en la colegiata de Santa María de Xätiva, por Francesc de Borja, obispo de Teano, más tarde arzobispo de Cosenza y cardenal.

Mármol blanco de fábrica romana (| 65 x $120 \mathrm{~cm}$.). Dos losas, una con la inscripción y otra superpuesta con escudo. Campo escritura (| $56 \times 112 \mathrm{~cm}$.). Altura de las letras $(4 \mathrm{~cm}$.), salvo la A inicial $(5 \mathrm{~cm}$.). En $1774 \mathrm{se}$ trasladó desde su capilla original, la primera entrando a mano derecha, a su ubicación actual.

Xàtiva. Colegiata de Santa María. Capilla de Nuestra Señora de la Soledad. Pared lateral izquierda.

FRANCISCUS DE BORJA, EPISCOPUS TEANENSIS / ALEXANDRI·VI PONT(ificis) MAX(imi) 'THESAURARIUS, / CAMERAE APOSTOLICAE PRAESIDENS, · / HANC CAPELLAM SUAE DOMUS MONUMENTUM / MARIAE VIRGINI DE FEBRIBUS • / QUATUORQUE ECCLESIAE DOCTORIBUS/ PIE EREXIT DICAVITQ(ue) / EX VOTO • / ANNO SALUTIS M CCCC LXXXX VII.

$-2-$

1500. Inscripciones conmemorativas de la finalización de la obra de la colegiata de Santa Maria de Gandía, por María Enríquez, duquesa viuda de Gandía, y su bijo Joan de Borja, III duque de Gandía.

Mármol blanco de fábrica romana ( 75 x $153 \mathrm{~cm}$.). Dos losas con sendas inscripciones complementarias, una a cada lado de la puerta de los Apóstoles. Tamaño de las letras ( $5^{\prime} 5$ x $5 \mathrm{~cm}$.), salvo la inicial agrandada.

Gandía. Colegiata de Santa María. Fachada exterior, colocadas a ambos lados de la puerta de entrada principal gótica.

ALEXANDER $\cdot$ VI, PONT(ifex) $\cdot$ MAX(imus), $\cdot$ SUPPLICE $\quad$ ILL(ustrisim) I $\cdot$ MARIA HENR(ices), /DUCE GAND(ie), HUIUS ECCL(esie) /COLLEGIUM INSTITUIT/ ANNO POST IESU NATALE(m)/MILLESIMO QUINGENTESI(m)O./

IMPENSA ET AUSPICIIS ILL(ustris[simae]) MARIAE/ HENRICES ET EIUS FILII IOHANNIS/ BORGIAE, DUCUM GANDIAE, A PORTA/ VETERI CITRA EST HOC FANUM REFE-/-CTUM ANNO QUINGENTESI(m)O SUPRA/ MILL(esimo) POST VIRGINEM ENIXAM. 
Vicente Pons Alós. ‘Gente Borgia’. Un nuevo ejemplo del mecenazgo de los Borja: Primeras inscripciones humanísticas en Valencia

\section{Bibliografía}

AAVV (1995) Damià Forment, escultor renacentista. Valencia, Fundación Bancaixa.

Aldana Fernández, S. (1988) La Lonja de Valencia. Valencia: Biblioteca Valenciana, 2 vols.

Batllori, M. (1994) La familia Borja: Obra completa. IV. València, Biblioteca d'Estudis i investigacions.

Bertaux, E. (1908) «Monuments et souvenirs des Borgia dans le Royaume de Valence», Gazette des Beaux-Arts, XXXIX (Paris), pp. 89-113, 198-220.

I Borgia (2002) Roma. Fondazione Memmo (3 ottobre 2002-23 febbraio 2003). Roma, Electa.

Campana, A. (2004) Studi epigrafici ed epigrafía nuova nel Rinascimento umanistico. Roma: Edizioni di Storia e Letteratura, 2005; Zamponi, S., «La scrittura umanistica», Archiv für Diplomatik, 50, pp. 467-504.

Bolufer, J.- Ribera, A. (1999) «Epigrafía valenciana medieval i moderna: les inscripcions sobre pedra», Alba. Revista d'Estudis Comarcals de la Vall d'Albaida, 13/14 (Ontinyent, Ajuntament), pp. 133 y ss.

Borgia, L. (2001) «La heráldica de los Borja desde los inicios hasta los primeros años del siglo XVI», en: Los Borja. Del mundo gótico al universo renacentista. Valencia, Generalitat Valenciana, 2001, pp. 225-244.

I Borgia (2002) Roma. Fondazione Memmo (3 ottobre 2002-23 febbraio 2003). Roma, Electa, especialmente pp. 170-171.

Casamassina, E. (1964) «Lettere antiche: note per la storia della reforma grafica umanistica», Gutenberg Jahrbuch, pp, 13-26.

- (1966) Trattati di scrittura del cinquecento italiano. Milano, Il Polifilo.

Castillo Gómez, A. (1997) Escrituras y escribientes, Prácticas de la cultura escrita en una ciudad del Renacimiento. Las Palmas de Gran Canaria, Gobierno de Canarias.

Cerda I Ballester, J.- Navarro Fajardo, J.C. (2017) El Castillo y Sacro Convento de la Orden de Montesa. Historia y arquitectura. Valencia: Universitat Politècnica de València.

Chiabo, M. Di- Gargano, M., a cura di (2013) Le roche Alesandrine e la rocca di Civita Castellana, Atti del Convegno (Viterbo, 19-20 marzo 2001), Roma nel Rinascimento.

Escolano, G.- Perales, J.B. (1878-1880) Décadas de la insigne y coronara ciudady Reino de Valencia. Valencia 1878-1880, vol. II.

Forcella, V. (1869-1884) Iscrizione delle chiese ed altri ediffici di Roma dal secolo XI fino ai giorni nostri. Roma, 14 vols.

Galletti Romani, Petri Aloysii (1760) Inscriptiones Romanae infimi Aevi Romanae exstantes. Romae: Typis generosi Salomoni bibliopolae, 3 vols. 
Vicente Pons Alós. ‘Gente Borgia’. Un nuevo ejemplo del mecenazgo de los Borja: Primeras inscripciones humanísticas en Valencia

Garcia, N. (2004) Arte, podery género en el Renacimiento español. Elpatronazgo artístico de Mencía de Mendoza. Murcia: Navisca.

- (2007-2008) «Modelos de enterramiento, modelos de patronazgo: la capilla de los tres Reyes del convento de Santo Domingo de Valencia y los marqueses de Zenete», Imafronte, 19-20, pp. 63-74.

Gargano, M. (2001) «Alessandro VI e l'antico: architettura e opere pubbliche tra magnificentia e liberalitas», Roma di fronte all'Europa al tempo di Alessandro VI. Atti del Convegno (Citta del VaticanoRoma, 1.4 diciembre 1999), a cura di M. Chiabò, S. Maddalo, M. Miglio, A.Mª. Oliva. Roma, Roma nel Rinascimento, vol. II, pp. 549-570.

Gascón Pelegrí, V. (1975) El Real monasterio de Santo Domingo. Capitanía general de Valencia. Valencia, Caja de Ahorros y Monte de Piedad.

Gimeno Blay, F.M. (1990) «Materiales para el estudio de las escrituras de aparato bajo medievales. La colección epigráfica de Valencia», en: Epigraphik 1988. Fachtagung für Mittelalterliche und Neuzeitliche epibraphik. (Wien: Österreichische Akademie der Wissenschaften), Herausgegeben von Walter Koch, pp. 195-216.

(2002) «A propósito de un tratado de caligrafia del Quattrocento italiano», Syntagma. Revista de Historia del Libro y de la Lectura, pp. 47-72.

- (2005) Admiradas mayúsculas. La recuperación de los modelos gráficos romanos. Salamanca: Fundación Germán Sánchez Ruipérez.

- (2002) «Capitales renacentistas, libros humanísticos. Representaciones de la cultura escrita en la pintura valenciana (XV-XVI)», Segni per Armando Petrucci. A cura di Luisa Miglio e Paola Supino. Roma: Ed. Bagatto Libri, pp. 159-175. El texto fue reeditado en la obra del mismo autor: Scripta manent. De las ciencias auxiliares a la historia de la Cultura Escrita. Granada: Universidad de Granada, 2008, pp. 171-191.

(2002) «Regola a fare letre antiche: A propósito de un tratado de caligrafía del Quattrocento italiano», Syntagma. Revista de Historia del Libro y de la Lectura, pp. 47-72.

- (2005) Admiradas mayúsculas. La recuperación de los modelos gráficos romanos. Madrid, Instituto de Historia del Libro y de la Lectura.

- (2008) «De la 'luxurians littera' a la 'castigata et clara'. De l'ordre gràfic medieval a l'humanísme (segles XV-XVI)», Studium Medievale. Revista de Cultura visual- Cultura escrita, 1, pp. 151-177.

- - (2015) «Mirae antiquitatis litterae quaerendae. Poniendo orden entre las mayúsculas», Culturas del escrito en el mundo occidental. Del Renacimiento a la contemporaneidad. A. Castillo Gómez (ed.). Madrid, Casa de Velázquez, pp. 19-32.

Gionta, D. (2005) Epigrafia umanistica a Roma. Messina.

González Baldoví, M. (2014) La capella de les febres de Xàtiva: 'Monumentum Domus Borgiae'. València, Institució Alfons el Magnànim. 
Vicente Pons Alós. ‘Gente Borgia’. Un nuevo ejemplo del mecenazgo de los Borja: Primeras inscripciones humanísticas en Valencia

Gonzalez Martí, M. (1952) Cerámica del Levante español. Siglos medievales. Tomo II. Alicatados y azulejos. Barcelona, ed. Labor.

Guerrini, P. (1986) «L'epigrafia Sistina come momento della 'restauratio Urbis' «,Un pontificato ed una città. Sisto IV (1471-1484). Atti del Convegno (Roma, 3-7 dicembre 1984), a cura di Miglio, M. et alii. Roma: Istituto Storico Italiano per il Medio Evo, pp. 453-468;

Guerrrini, P.- Maddalo, S.- Niutta, F.- Porro, D. (1986) «Iscrizioni Romanae Sistine, Appendice», Un pontificato ed una città. Sisto IV (1471-1484). Atti del Convegno (Roma, 3-7 dicembre 1984), a cura di Miglio, M. et alii. Roma: Istituto Storico Italiano per il Medio Evo, pp. 469-482.

Hollingsworth, M. (2002) El patronazgo artístico en la Italia del Renacimiento de 1400 a principios del s. XVI. Madrid, ed. Akal, pp. 288-292.

Juan Redal, E.- Juan Caballer, J. (2009) «La nobleza valenciana al servicio de los Habsburgo: los Pardo de la Casta, señores de Alaquàs (1610-1650)», Quaderns d'investigació d'Alaquàs, pp. 9-68.

Kajanto, L. (1982) Papal Epigraphy in Renaissance Rome. Helsinki, Suomalainen Tiedeakatemia. . (1989) «L'epigrafia latina a Roma nel quattrocento», Roma nel Rinascimento, pp. 73-84.

Mandingorra Llavata, M . L. (1986) «La escritura humanística en Valencia: su introducción y difusión en el s. XV», Estudis Castellonencs, 3, pp. 5-94.

Martinez Talón, P. (2017) 'Aperire abscondita'. Inscripciones de la Catedral de Valencia. Valencia, Universitat de València. Trabajo de final de máster.

Montesano, M. (2001) «Il toro dei Borgia: analisi di un símbolo fra tradizione araldica e suggestioni pagane», en: Roma di fronte all'Europa al tempo di Alessandro VI. Atti del Convegno (Citta del VaticanoRoma, 1.4 diciembre 1999), a cura di M. Chiabò, S. Maddalo, M. Miglio, A.Mª Oliva. Roma, Roma nel Rinascimento, vol. III, pp. 759-780.

Niutta, F. (1986) «Temi e personaggi nell'epigrafia sistina», Un pontificato ed una città. Sisto IV (14711484). Atti del Convegno (Roma, 3-7 dicembre 1984), a cura di Miglio, M. et alii. Roma: Istituto Storico Italiano per il Medio Evo, pp 381-408.

(2002) «Il Romanae historia compendium di Pomponio Leto dedicato a Francesc Borgia», Canfora, D.- Chiabo, M.- Nichilo, M. de (eds.), Principato eclesiástico e riuso dei classiici gli umanisti e Alessandro VI. Atti del Convegno (Bari - Monte Sant-Angelo, 22-24 maggio 2000), Roma nel Rinascimento, pp. 321-354.

Nyberg, U. (1986) «The paleography of the epigraph of Martin V and the origin of humanistic script», in Un pontificato ed una città. Sisto IV (1471-1484), a cura de M. Miglio e altri, Roma, pp. 33-42.

Onofrio, C. d' (1978) Castel S. Angelo e borgo tra Roma e papato. Roma, Romana Società editrice.

Paolucci, A. (2016) Scritture e simboli del potere pontificio in età moderna. Lapidi e stemmi sui muri di Roma. Roma, Ed. Artemide. 
Vicente Pons Alós. ‘Gente Borgia’. Un nuevo ejemplo del mecenazgo de los Borja: Primeras inscripciones humanísticas en Valencia

Pastor Zapata, J.L. (1992) Gandía en la Baixa Edat Mitjana. La vila i el senyoriu dels Borja. Oliva, CEIC Alfons el Vell.

Pellicer i Rocher, V.- Company i Climent, X. (2002) «La evolución constructiva y arquitectónica de l'església col legiata de Santa María de Gandía», Herrero, A. (coord.), La Seu-Colegiata de Santa María de Gandía. Gandía, Asociación Amics de la Seu, pp. 65-128.

Pellicer i Rocher, V. (2011) La Colegiata de Gandía. Conmemoración de la reinstauración de la Colegiata (1911-2011). Gandía, Ajuntament.

Pereira García, I. (2016) «La escritura humanística en la Rioja: ejemplos epigráficos», en: 'Dicebamus hesterna die'. Estudios en homenaje de Pedro J. Arroyal Espigares y $M^{a}$. Teresa Martín Palma. Málaga, Encaso ed., pp. 343- 364.

Pérez Giménez, J.I. (2014) Thesaurus Collegiatae: Historia y avatares del patrimonio artístico de la Seu de Xàtiva. Xàtiva, Colegiata de Santa María de Xàtiva.

Petrucci, A. (1985) «Potere, spazi urbani, scritture esposte: proposte ed esempi», Culture et ideologie dans la genése de l'état Moderne. Actes de la table ronde organisée par le Centre National de la Recherche Scientifique et l'École française de Rome, Rome: École Française de Rome, pp. 85-97.

(1986) La scrittura. Ideologia e rappresentazione. Torino: Einaudi.

. (1994) «Pomponio Leto e la rinascita dell'epitaffio antico», en: Vox lapidum, dalla riscoperta delle iscrizioni antiche all'invenzioni di un nuovo stile scrittorio, Atti del Convegno internazionale, Eutopia, 3, pp. 19-44.

Pons Alós, V. (1996) «Els Borja en l’Heràldica», Els Temps dels Borja, València, Generalitat ValencianaConsell Valencià de Cultura, pp. 225-254;

(1997) «El testamento nuncupativo del conde Corella: la solemnidad de un privilegio», Alberri. Centre d'Estudis Contestans, 10, pp. 87-110.

—_. (2002) «L'heràldica dels Borja», Diplomatari Borja, 1, pp. 163-181;

. (2005), «Francesc de Borja, el cardenal humanista», en: Cardenales y prelados de Xátiva en la época de los Borja. Xàtiva, Centro de Estudios Borgianos, pp. 94-96, 99-101.

- (2013) La Iglesia en Xàtiva. Textos y documentos. Xàtiva, Aula de Cultura beato Gonzalo Viñes.

- (2014) «El clergat valencià a les darreries de l'Edat mitjana», en: SOLER, Abel, Joan Roís de Corella (1435-1497). Sintesi biográfica $i$ aportació documental. València, Acadèmia Valenciana de la Llengua, pp. 65-84.

Porro, D. (1986) «La restituzione della capitale epigráfica nella scrittura monumentale: epitafi ed iscrizioni celebrative», in Un pontificato ed una città. Sisto IV (1471-1484), a cura de M. Miglio e altri, Roma, pp. 409-427.

Ramirez Sánchez, M. (2012) «La tradición de la epigrafía antigua en las inscripciones hispanas de los siglos XV y XVI», Veleia, 29, pp. 255-277. 
Vicente Pons Alós. ‘Gente Borgia’. Un nuevo ejemplo del mecenazgo de los Borja: Primeras inscripciones humanísticas en Valencia

Redondo Cantera, M . J. (1986) «El sepulcro de Sixto IV y su influencia en la escultura del Renacimiento en España», Boletín del Seminario de Estudios de Arte y Arqueología, 52, pp. 271-282.

Sanchis Sivera, J. (1909) La Catedral de Valencia. Guia histórica y artística. Valencia: Imprenta de F. Vives Mora.

Tormo Monzó, E. (1942) Monumentos de españoles en Roma y de portugueses e hispanoamericanos. Madrid.

Villalona, Ma. A. (ed) (1986) Jeroni Pau. Obres. Barcleona, Curial, 2 vols.

Villalonga, M. (1982) «Una inscripció de Jeroni Pau a Subiaco», Faventia, 4/2, pp. 99-105.

Zamponi, S. (2004) «La scrittura umanistica», Archiv für Diplomatik, 50, pp. 467-504

SCRIPTA, Revista internacional de literatura i cultura medieval $i$ moderna, núm. 13 / juny 2019 / pp. 22 - 44 ISSN: 2340-4841 · doi:10.7203/SCRIPTA.13.15474 
Vicente Pons Alós. 'Gente Borgia’. Un nuevo ejemplo del mecenazgo de los Borja: Primeras inscripciones humanísticas en Valencia

\section{LÁMINAS}

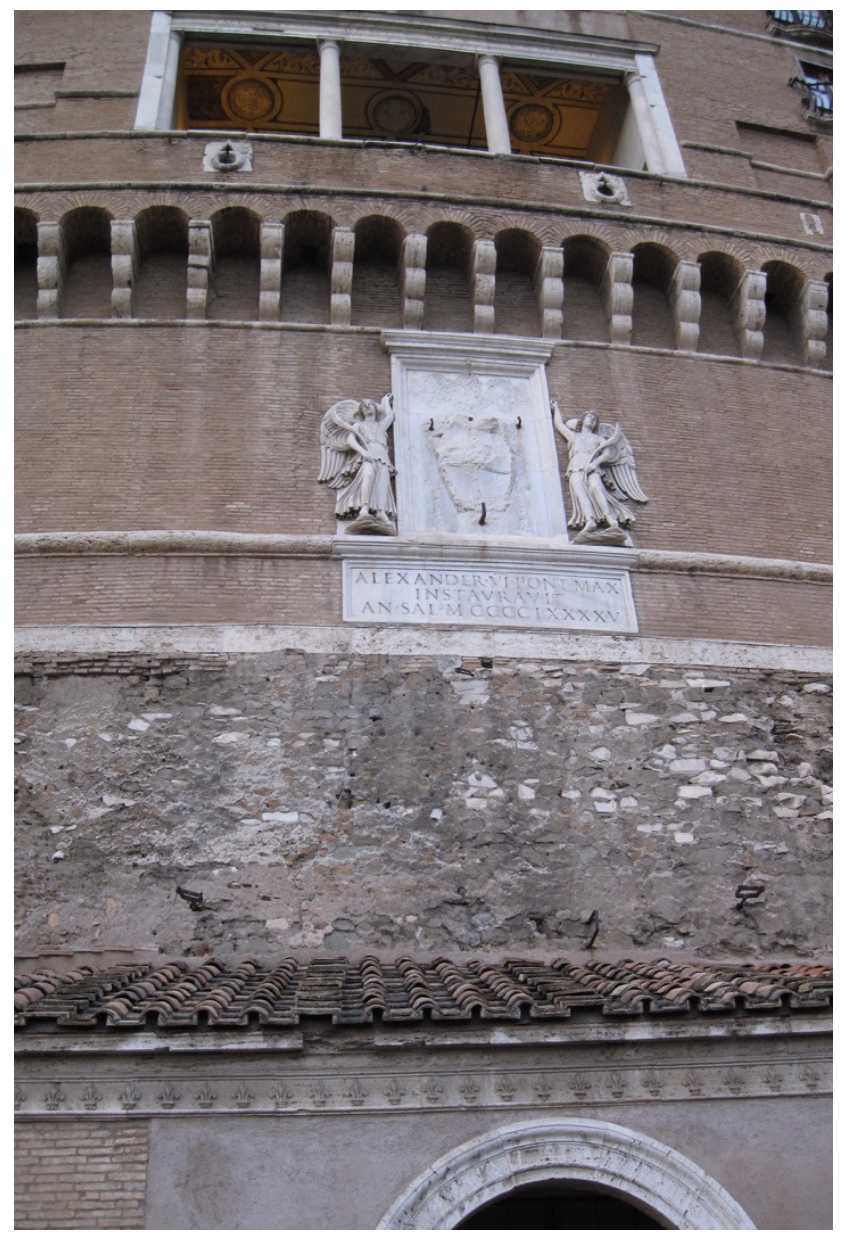

Lám. 1.: Inscripción del pontificado Alejandro VI (1495). Castel Sant’Angelo. Roma.

SCRIPTA, Revista internacional de literatura i cultura medieval $i$ moderna, núm. 13 / juny 2019 / pp. 22 - 44 ISSN: 2340-4841 $\cdot$ doi:10.7203/SCRIPTA.13.15474 
Vicente Pons Alós. ‘Gente Borgia'. Un nuevo ejemplo del mecenazgo de los Borja: Primeras inscripciones humanísticas en Valencia

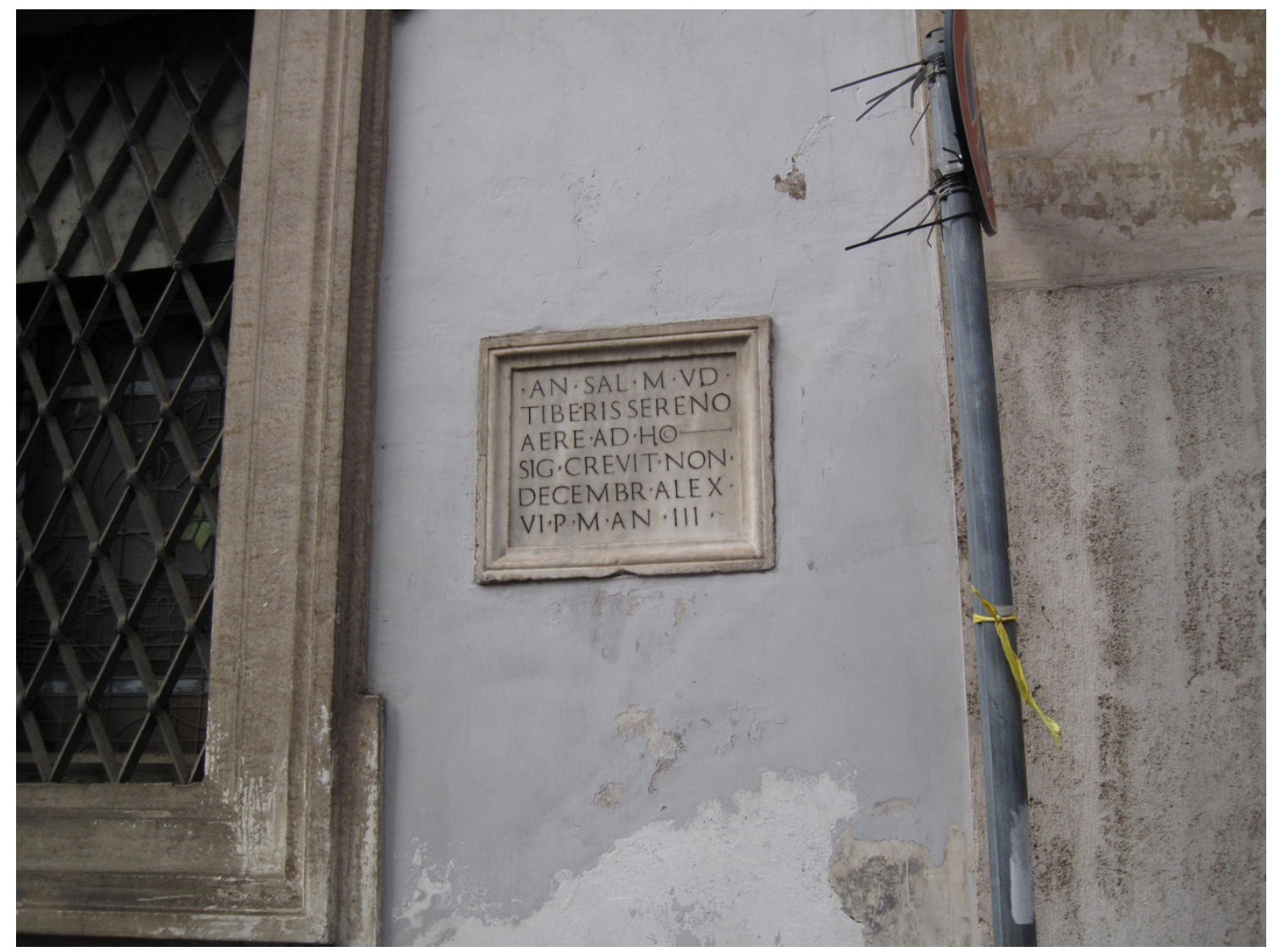

Lám. 2.: Inscripción del pontificado Alejandro VI (1495). Via della Palombella. Roma.

SCRIPTA, Revista internacional de literatura i cultura medieval $i$ moderna, núm. 13 / juny 2019 / pp. 22 - 44 ISSN: 2340-4841 · doi:10.7203/SCRIPTA.13.15474 
Vicente Pons Alós. 'Gente Borgia'. Un nuevo ejemplo del mecenazgo de los Borja: Primeras inscripciones humanísticas en Valencia

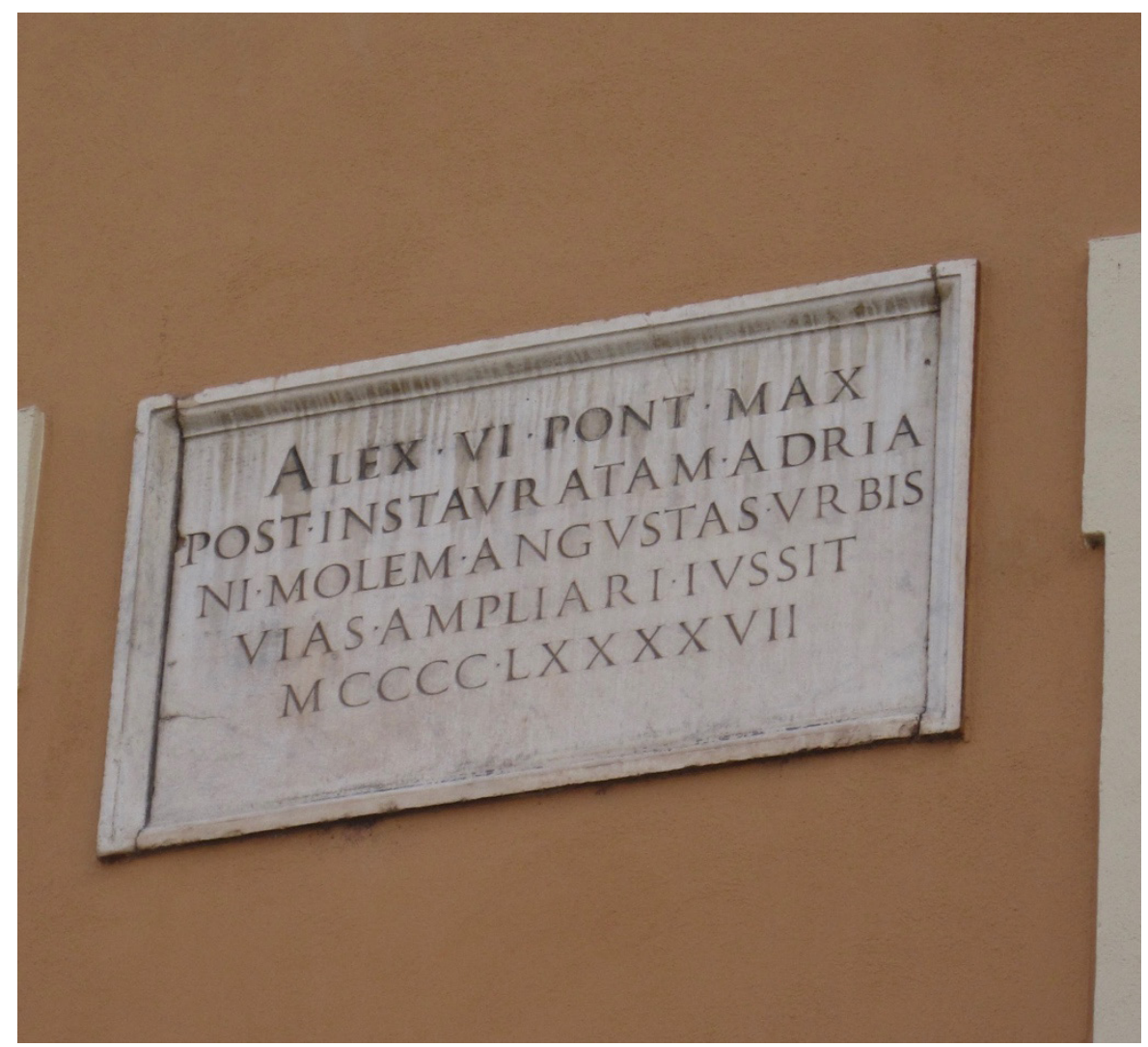

Lám. 3.: Inscripción del pontificado Alejandro VI (1497). Via del Pellegrino. Roma.

SCRIPTA, Revista internacional de literatura i cultura medieval i moderna, núm. 13 / juny 2019 / pp. 22 - 44 ISSN: 2340-4841 $\cdot$ doi:10.7203/SCRIPTA.13.15474 
Vicente Pons Alós. ‘Gente Borgia'. Un nuevo ejemplo del mecenazgo de los Borja: Primeras inscripciones humanísticas en Valencia

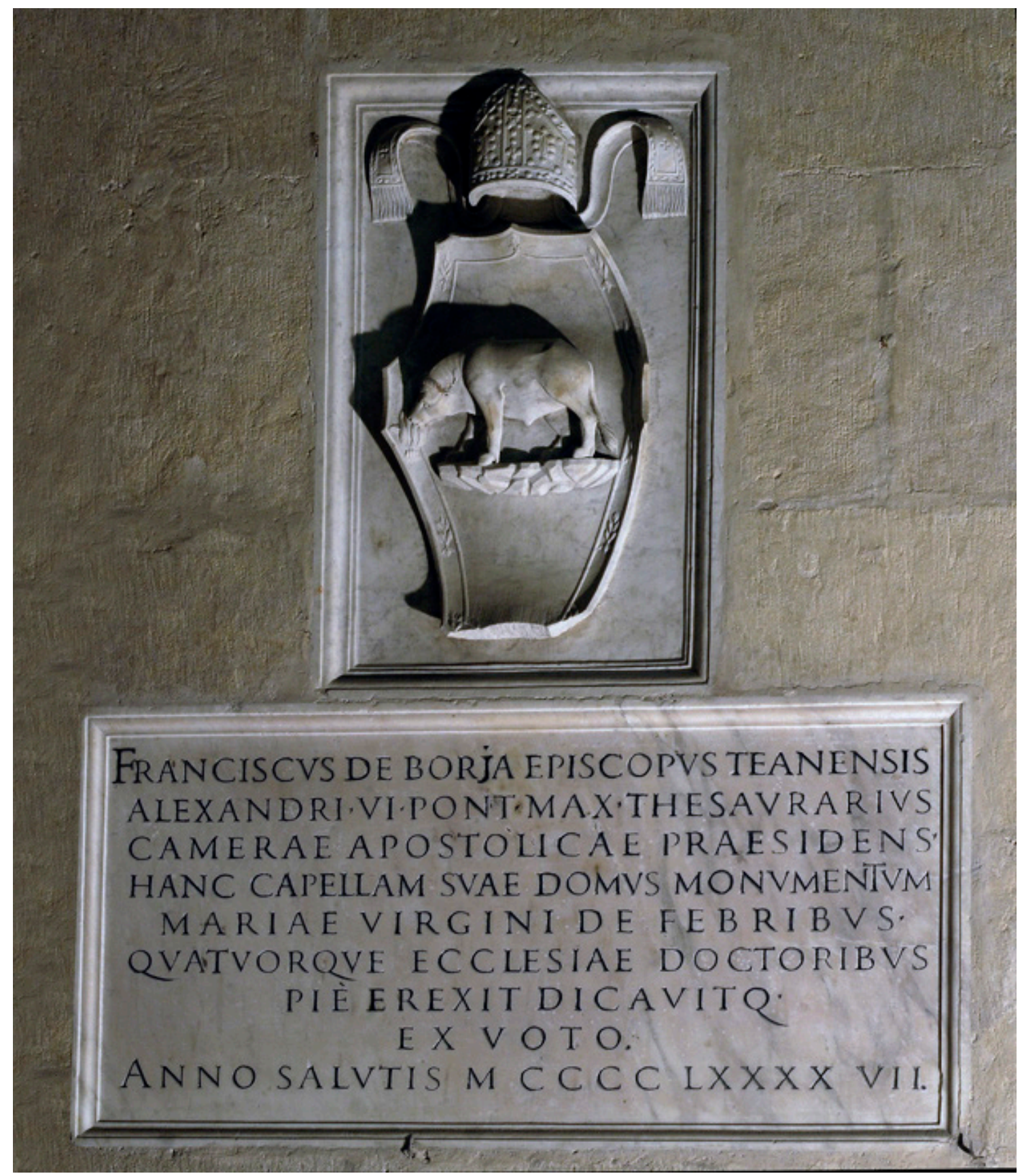

Lám. 4.: Inscripción conmemorativa de la construcción de la capilla de la Mare de Déu de les Febres por Francesc de Borja, obispo de Teano (1497). Colegiata de Santa María. Xàtiva.

SCRIPTA, Revista internacional de literatura i cultura medieval i moderna, núm. 13 / juny 2019 / pp. 22 - 44 ISSN: 2340-4841 $\cdot$ doi:10.7203/SCRIPTA.13.15474 
Vicente Pons Alós. ‘Gente Borgia'. Un nuevo ejemplo del mecenazgo de los Borja: Primeras inscripciones humanísticas en Valencia
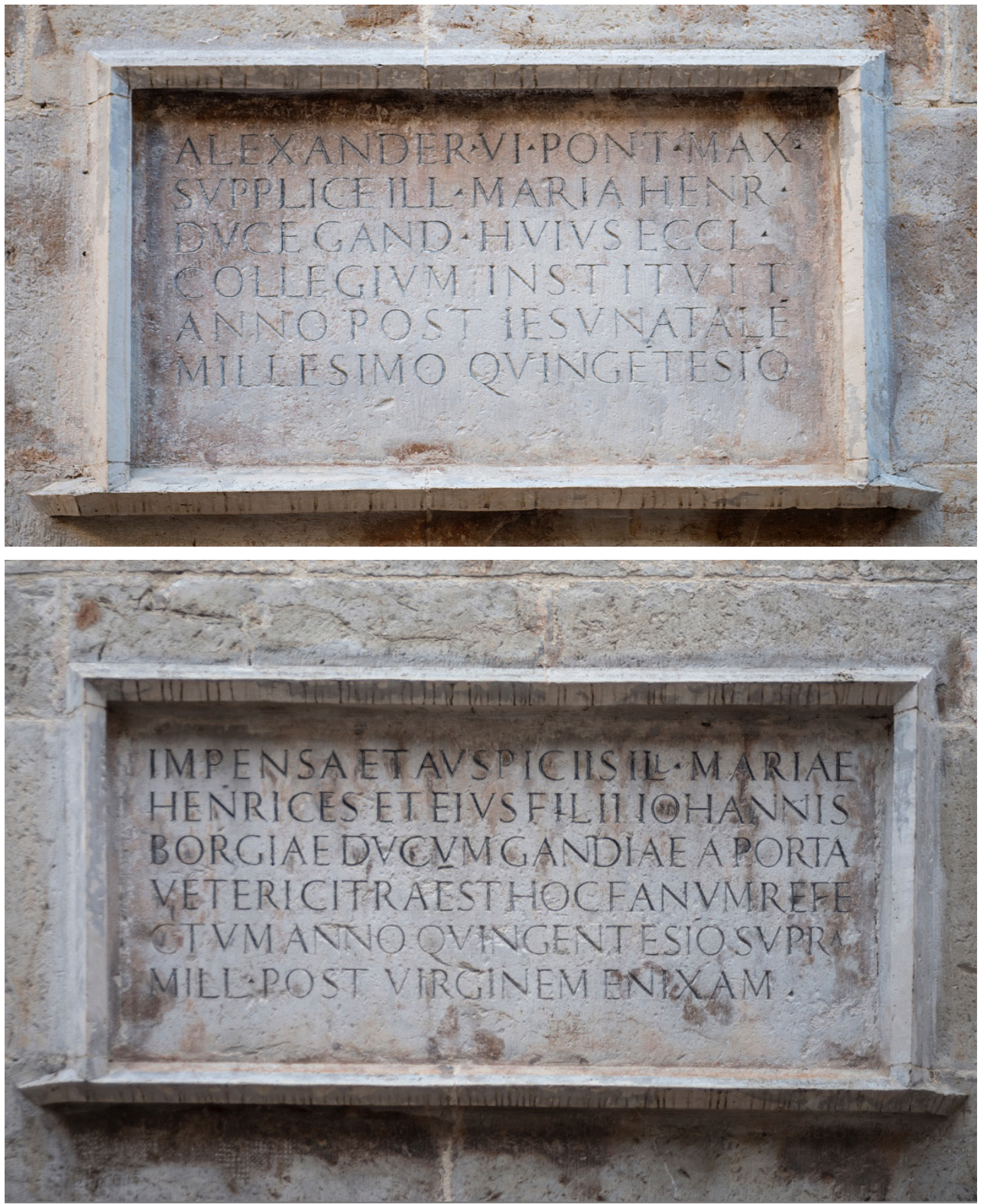

Lám. 5 y 6.: Inscripciones conmemorativas de las obras de la Puerta de los Apóstoles por María Enríquez, duquesa viuda de Gandía, y su hijo Joan de Borja, III duque de Gandía (1500). Colegiata de Santa María.

SCRIPTA, Revista internacional de literatura i cultura medieval i moderna, núm. 13 / juny 2019 / pp. 22 - 44 ISSN: 2340-4841 $\cdot$ doi:10.7203/SCRIPTA.13.15474 
Vicente Pons Alós. 'Gente Borgia’. Un nuevo ejemplo del mecenazgo de los Borja: Primeras inscripciones humanísticas en Valencia

Gandía.

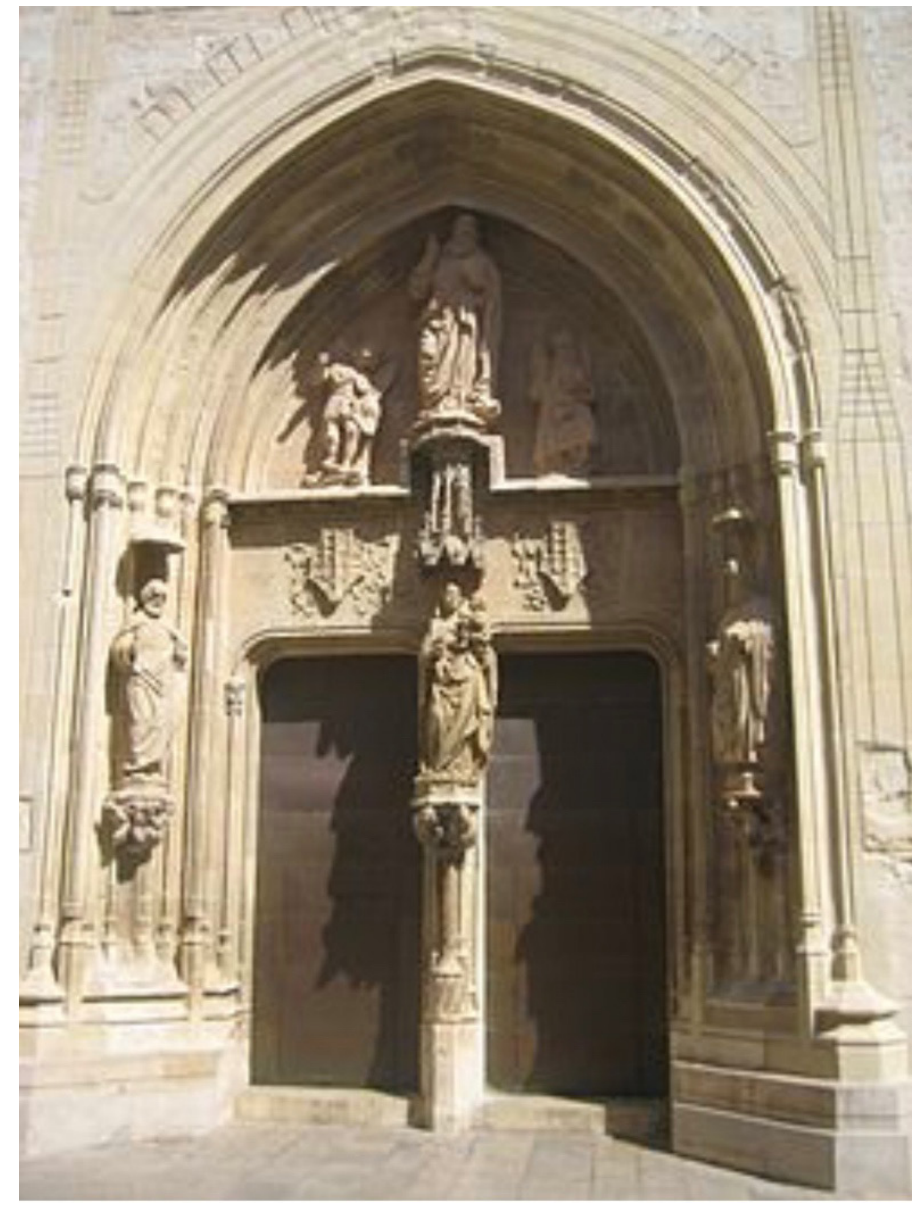

Lám. 7 A.: Puerta de los Apóstoles. Colegiata de Santa María. Gandía.

SCRIPTA, Revista internacional de literatura i cultura medieval $i$ moderna, núm. 13 / juny 2019 / pp. 22 - 44 ISSN: 2340-4841 · doi:10.7203/SCRIPTA.13.15474 
Vicente Pons Alós. 'Gente Borgia'. Un nuevo ejemplo del mecenazgo de los Borja: Primeras inscripciones humanísticas en Valencia

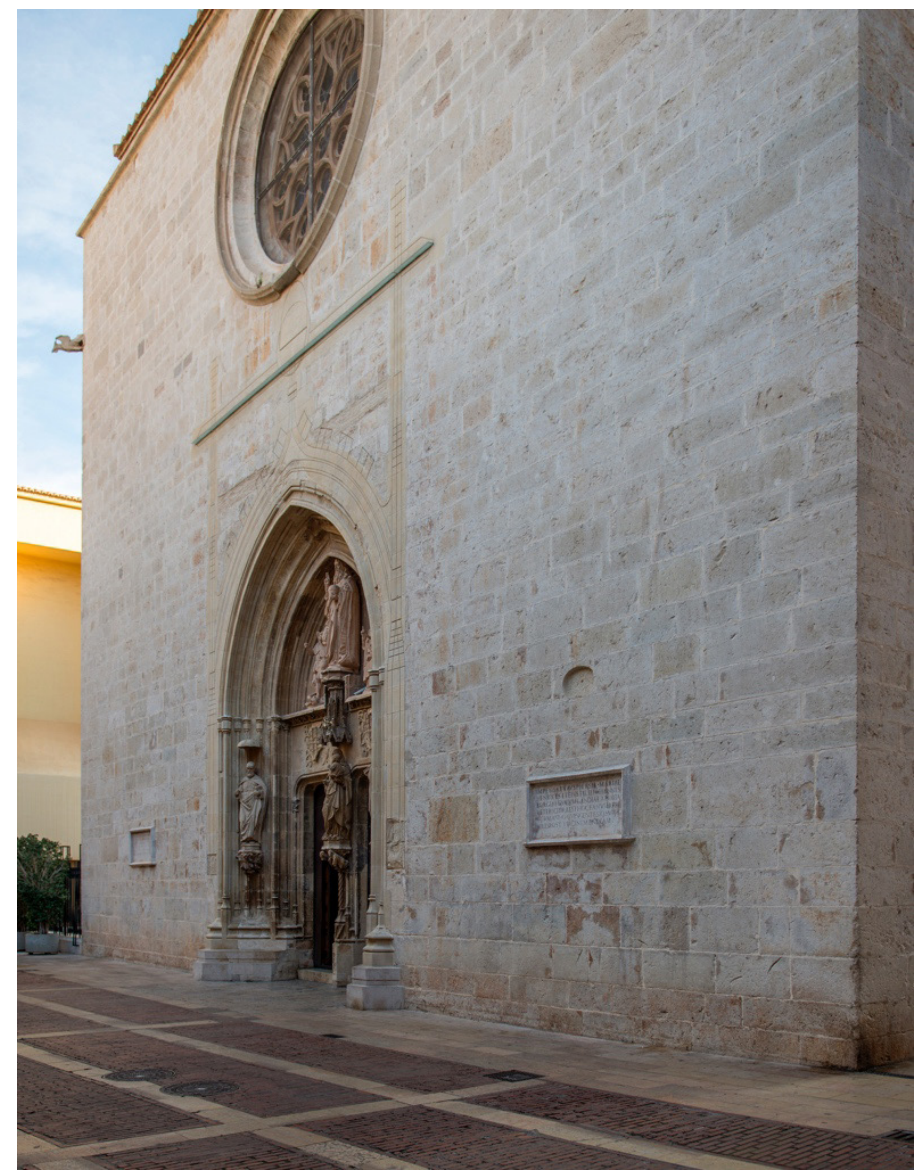

Lám. 7 B.: Puerta de los Apóstoles. Colegiata de Santa María. Gandía.

SCRIPTA, Revista internacional de literatura i cultura medieval $i$ moderna, núm. 13 / juny 2019 / pp. 22 - 44 ISSN: 2340-4841 $\cdot$ doi:10.7203/SCRIPTA.13.15474 
Vicente Pons Alós. ‘Gente Borgia'. Un nuevo ejemplo del mecenazgo de los Borja: Primeras inscripciones humanísticas en Valencia

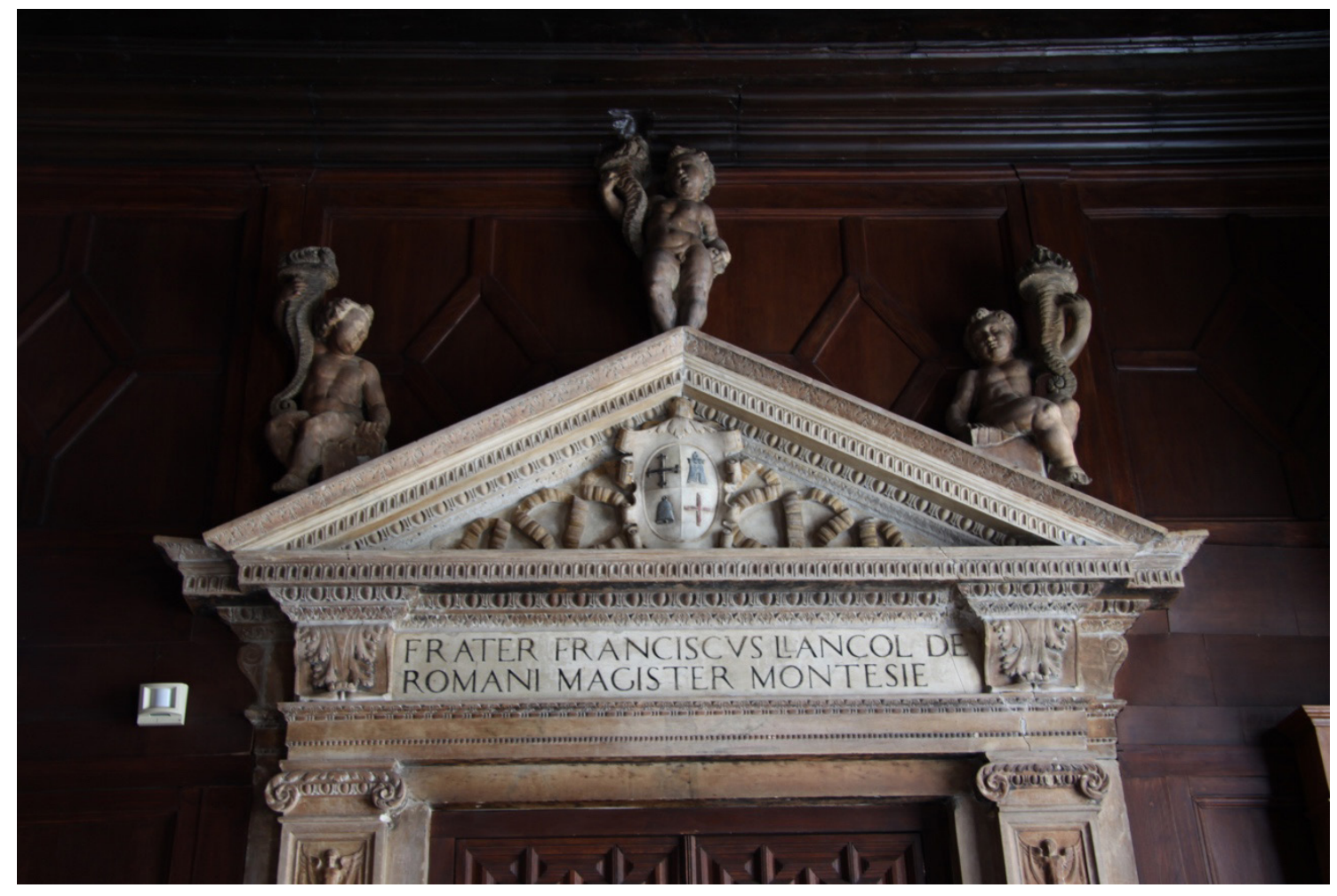

Lám. 8.: Inscripción alusiva a Francesc Llançol de Romaní, maestre de la Orden de Montesa (1537-1544).

Palacio de la Generalitat Valenciana. Valencia. Procede del castillo de Montesa.

SCRIPTA, Revista internacional de literatura i cultura medieval i moderna, núm. 13 / juny 2019 / pp. 22 - 44 ISSN: 2340-4841 $\cdot$ doi:10.7203/SCRIPTA.13.15474 